\title{
Intensive Care Management of Prostodin-induced Acute Pulmonary Edema in a Parturient
}

\author{
${ }^{1}$ Sairem Mangolnganbi Chanu, ${ }^{2}$ Samarjit Dey, ${ }^{3}$ Subrat Panda, ${ }^{4}$ Indubala Maurya
}

\begin{abstract}
Pulmonary edema in parturient can be because of various reasons. Parturients are at risk of pulmonary edema because of the physiological changes. Here, we report successful management of a case of pulmonary edema caused by prostodin (Carboprost) given within a maximal dose limit. Prostodin acts as a smooth muscle stimulant and is a recognized second-line agent for use in the management of postpartum uterine atony unresponsive to oxytocin/ergometrine. It may induce pulmonary edema but rare in limited doses. However, vigilant monitoring and timely intensive care management helped us successfully to manage the case.
\end{abstract}

Keywords: Carboprost, Pregnancy, Pulmonary edema.

How to cite this article: Chanu SM, Dey S, Panda S, Maurya I. Intensive Care Management of Prostodin-induced Acute Pulmonary Edema in a Parturient. J South Asian Feder Obst Gynae 2015;7(3):218-219.

Source of support: Nil

Conflict of interest: None

Date of received: 16 September 2015

Date of acceptance: 20 October 2015

Date of publication: December 2015

\section{INTRODUCTION}

A 28-year-old lady, G2P1Lo at her 37th weeks of gestation, was taken up for emergency cesarean section for fetal distress with bleeding PV. Blood sugar was under control. Her preoperative investigations were within normal limits. Informed consent was obtained after explaining all anesthetic concerns to the patient and her relatives.

In the preoperative area, she was conscious, oriented with blood pressure $90 / 54 \mathrm{~mm} \mathrm{Hg}$, pulse rate $112 / \mathrm{min}$,

\footnotetext{
${ }^{1,2,4}$ Senior Resident, ${ }^{3}$ Associate Professor

${ }^{1}$ Department of Obstetrics and Gynecology, Jawaharlal Institute of Postgraduate Medical Education and Research Puducherry, India

${ }^{2,4}$ Department of Anesthesiology, Jawaharlal Institute of Postgraduate Medical Education and Research, Puducherry, India

${ }^{3}$ Department of Obstetrics and Gynecology, North Eastern Indira Gandhi Regional Institute of Health and Medical Sciences Shillong, Meghalaya, India

Corresponding Author: Sairem Mangolnganbi Chanu Senior Resident, Department of Obstetrics and Gynecology Jawaharlal Institute of Postgraduate Medical Education and Research, Puducherry, India, Phone: 04132298054, e-mail: dr.mangol123@gmail.com
}

and oxygen saturation $100 \%$ on FM with $\mathrm{O}_{2} @ 6$ LPM. As she was actively bleeding through per vaginum two 16 G IV cannula were inserted and fluid started. In view of acute fetal distress, it was decided to administer general anesthesia for the cesarean section. She was preoxygenated with $100 \% \mathrm{O}_{2}$ for 3 minutes and rapid sequence intravenous induction performed with $100 \mathrm{mg}$ ketamine, $100 \mathrm{mg}$ succinylcholine, patient was intubated with $7 \mathrm{~mm}$ ID ET tube using Sellick's maneuver. Anesthesia was maintained with $\mathrm{O}_{2}$, isoflurane along with vecuronium bromide. After 7 minutes, the baby was delivered after which inhalational agent was reduced to $\leq 1 \%$. Patient was administered inj fentanyl $100 \mu \mathrm{g}$ intravenously for analgesia after the baby was delivered. Oxytocin infusion was started at the rate of approximately $0.04 \mathrm{mIU} / \mathrm{min}$. However, the patient went into postpartum hemorrhage (PPH) due to uterine atony, which did not even respond to an increase in the rate of oxytocin infusion. Massaging was started. Inhalation agents were turned off. The patient lost about 1.8 to $2 \mathrm{~L}$ of blood. Intraoperatively, the placenta was found to be central-posterior and accreta type. Manual removal of complete placenta was done. Prostaglandin F2-alpha-carboprost trometamol $0.25 \mathrm{mg}$ (Prostodin, AstraZeneca, India). Single dose of prostodin was not so helpful, so subsequent one more dose was administered (after 10-15 minutes). Two and half liters crystalloids and one PC were transfused. Mean arterial pressure maintained above $65 \mathrm{~mm} \mathrm{Hg}$. Meanwhile, $\mathrm{PPH}$ was controlled and the uterine closure was started. As the skin incision was closed, a trend in rise of peak airway pressure and $\mathrm{SpO}_{2}$ drop was observed by the anesthesiologist. Auscultation revealed B/L crepitations. Provisional diagnosis of acute pulmonary edema was made and immediately injection frusemide $40 \mathrm{mg}$ and injection morphine $4.5 \mathrm{mg}$ was administered IV. Intraoperatively, fluid administered was $1000 \mathrm{ml}$ crystalloid.

Neuromuscular blockade was not reversed and the patient was shifted to intensive care unit (ICU) for further management. Postoperative electrocardiogram did not reveal any fresh changes but chest $\mathrm{X}$-ray was suggestive of pulmonary edema (Fig. 1) and was also confirmed by ultrasound. In ICU, patient was immediately put on Vigileo hemodynamic monitoring (EV 1000, Edwards Lifesciences, United States) which revealed a high systemic vascular resistance (SVR), and a low stroke volume (SV), a low normal cardiac index (CI) and excess 

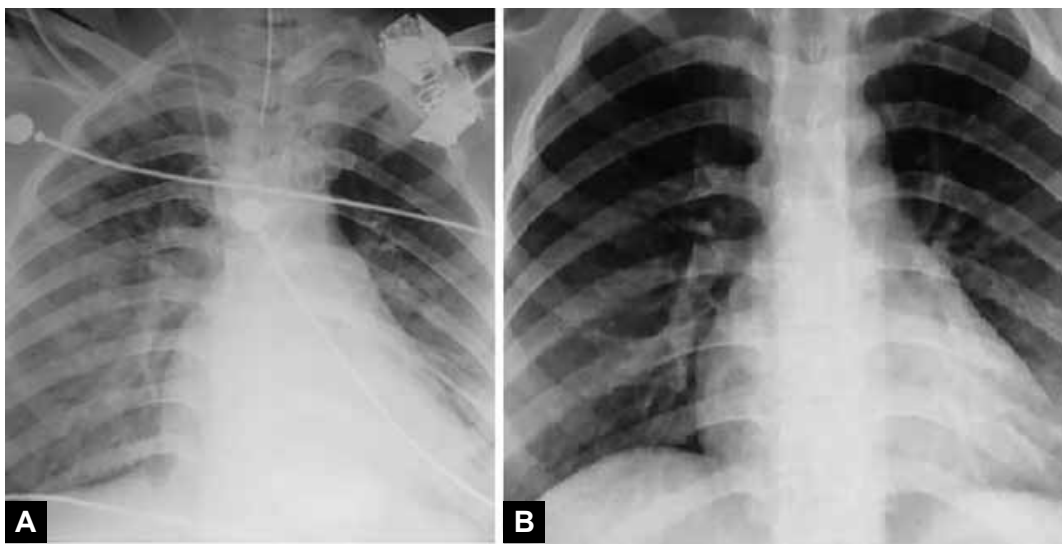

Figs 1A and B: Development and resolution of pulmonary edema

extravascular lung water (EVLW). Infusion dobutamine was started @ $5 \mathrm{mcg} / \mathrm{kg} / \mathrm{min}$. Systemic vascular resistance reduced gradually with improvement in SV and CI. Injection frusemide $40 \mathrm{mg}$ and morphine $4.5 \mathrm{mg}$ was repeated. Echocardiography $(\mathrm{ECHO})$ heart was asked for which revealed trace mitral regurgitation, trace tricuspid regurgitation and no other abnormalities. Chest was clear after 6 hours (Figs 1A and B). It was also evidenced by auscultation, chest X-ray, EVLW. $\mathrm{PaO}_{2} / \mathrm{FiO}_{2}$ was 326 . Patient was successfully extubated subsequently and kept on FM with $\mathrm{O}_{2} @ 5$ LPM in a propped up position and gradually weaned off from $\mathrm{O}_{2}$.

\section{DISCUSSION}

Prostodin [15-methyl prostaglandin (PG) F2-alpha, Astra Zeneca Pharma, London] acts as a smooth muscle stimulant and is a recognized second-line agent for use in the management of postpartum uterine atony unresponsive to oxytocin/ergometrine. It is an analog of PG F2-alpha (dinoprost) with a longer duration of action than its parent compound, attributed to its resistance to inactivation by oxidation at the 15-position. Available in single-dose vials of $0.25 \mathrm{mg}$, it may be administered by deep intramuscular injection or, alternatively, by direct intramyometrial injection. The latter route of administration is achieved either under direct vision at cesarean section or transabdomen or transvaginal following vaginal delivery and has the advantage of a significantly quicker onset of action. Peripheral intramuscular injection yields peak plasma concentrations at 15 minutes in contrast to less than 5 minutes for the intramyometrial route. Side effects of PG F2-alpha are related to its effects on smooth muscles. They include nausea, vomiting, diarrhea, bronchospasm and systemic hypertension. ${ }^{1}$

Secher et $\mathrm{al}^{2}$ found a $40 \%$ increase in cardiac output in pregnant anesthetized women during infusion of $300 \mu \mathrm{g}$ of PG F2-alpha with an increase in pulmonary arterial pressure, doubling of pulmonary vascular resistance and increase in airway resistance.
Cardiovascular collapse along with left heart failure has been reported with overdose of intramyometrial prostodin, the possible etiology being a combination of acute pulmonary hypertension with decreased left ventricular end-diastolic pressure and decreased cardiac output. ${ }^{3}$

Rodríguez de la et $\mathrm{al}^{4}$ reported a case of pulmonary edema related to administration of 15-methylprostaglandin F2-alpha during a cesarean section. After delivery, uterine atony was treated unsuccessfully with oxytocin and methylergometrine maleate; the obstetrician then gave an intramyometrial injection of $0.25 \mathrm{mg}$ of 15-methyl-prostaglandin F2-alpha (PGF2-alpha). After 5 minutes, $\mathrm{SpO}_{2}$ fell to $89 \%$, accompanied by dyspnea and sinus tachycardia of 130 to 140 beats/min, with normal cardiorespiratory sounds. The patient was transferred to the postoperative recovery unit, where a chest radiograph led to a diagnosis of acute pulmonary edema.

In our case, even though the single administration dose of prostaglandin F2-alpha was kept below the maximum dose range the pregnant physiology puts the parturient at risk of pulmonary edema. With no other significant cardiac or respiratory diseases, we can say that prostaglandin F2-alpha induced the sequence of pulmonary edema in our patient. We should be cautious while administering prostaglandin F2-alpha in a suspected PPH patient.

\section{REFERENCES}

1. Baduni N, Sanwal MK, Jain A. Acute pulmonary edema after intramyometrial prostodin. J Anaesthesiol Clin Pharmacol 2011 Apr;27(2):275-277.

2. Secher NJ, Thayssen P, Arnsbo P, Olsen J. Effect of prostaglandin E2 and F2 alpha on the systemic and pulmonary circulation in pregnant anesthetized women. Acta Obstet Gynecol Scand 1982;61(3):213-218

3. Douglas MJ, Farquharson DF, Ross PL, Renwick JE. Cardiovascular collapse following an overdose of prostaglandin F 2-alpha: a case report. Can J Anaesth 1989 Jul;36(4):466-469.

4. Rodríguez de la Torre MR, Gallego Alonso JI, Gil Fernández M. Pulmonary edema related to administration of 15-methylprostaglandin F2-alpha during a cesarean section. Rev Esp Anestesiol Reanim 2004 Feb;51(2):104-107. 